\title{
Uma análise crítica do discurso de preceptores em processo de formação pedagógica
}

Guilherme Torres Correa*,

Teresa Rachel Junqueira Carbone**,

Mariana Freitas de Assis Pereira Rosa***,

Gabriel Dória Marinho****

Victoria Maria Brant Ribeiro*****,

José Inacio Jardim Motta $* * * * *$

http://dx.doi.org/10.1590/0103-7307201507808

\section{Resumo}

Neste trabalho é analisada a construção coletiva de um discurso pedagógico realizado por preceptores do campo da saúde que passaram por um processo de formação pedagógica. Preceptores são profissionais que, em sua prática clínica, atuam como educadores, acompanhando discentes e residentes em formação. 0 artigo é constituído por duas partes: $A$ Prática da Preceptoria em Saúde, em que se trata de sua definição, problemas e desafios, apontando um curso de formação como uma estratégia educacional relevante; e Análise Crítica do Discurso, em que se usa metodologia homônima para se debruçar sobre as sinteses coletivas dos preceptores, no sentido de melhor entender os discursos presentes em seus textos e avaliar a apropriação dos conteúdos trabalhados. Constatou-se que, ao mesmo tempo em que a produção discursiva coletiva é um exercício pedagógico enriquecedor, também é um processo desafiador que demanda paciência e dedicação das partes envolvidas para se alcançar o objetivo proposto.

Palavras-chave: : Análise Crítica do Discurso, preceptoria, formação pedagógica
* Programa de Pós-Graduação em Educação, Faculdade de Educação, Universidade de São Paulo - USP, São Paulo, SP, Brasil.

correa.gt@gmail.com

** Médica, ex-aluna de Iniciação Científica da Faculdade de Medicina da Universidade Federal do Rio de Janeiro - UFRJ, Rio de Janeiro, RJ, Brasil. tete_ junqueira@yahoo.com.br

*** Médica- ex-aluna de Iniciação Científica da Faculdade de Medicina da da Universidade Federal do Rio de Janeiro - UFRJ, Rio de Janeiro, RJ, Brasil. marifreitasrosa@hotmail.com

$* * * *$ Aluno da Faculdade de Medicina da Universidade Federal do Rio de Janeiro - UFRJ, Rio de Janeiro, RJ, Brasil.gdoriam@gmail.com

***** Professora Associada. Programa de Pós-Graduação em Clínica Médica da Universidade Federal do Rio de Janeiro - UFRJ, Rio de Janeiro, RJ, Brasil. victoria.brantr@gmail.com

****** Doutor em Educação em Ciências e Saúde NUTES / Universidade Federal do Rio de Janeiro UFRJ; Pesquisador da Escola Nacional de Saúde Pública - FIOCRUZ, Rio de Janeiro, RJ, Brasil. inacioj@uol.com.br 


\title{
A critical analysis of preceptors' discourse in a process of teacher training
}

\begin{abstract}
This article analyzes the collective construction of pedagogical discourse by preceptors that underwent a pedagogical training program. Preceptors are health professionals who act in their clinical practice as educators, instructing students and residents. The first section discusses the field main definitions, problems and challenges, and argues for the relevance of pedagogical training for preceptors. The second section uses Critical Discourse Analysis to investigate the preceptors' collective synthesis produced in the training final stages. The article shows that while the collective discursive production is an enriching pedagogical exercise, it is also a challenging process that requires patience and dedication of those involved to achieve the training goals.
\end{abstract}

Keywords: Critical Discourse Analysis, preceptor, teaching training 


\section{Introdução}

O objetivo deste trabalho é analisar a construção coletiva de um discurso pedagógico realizado por preceptores do campo da saúde que passaram por um processo de formação pedagógica. Para a condução deste estudo, optamos pelo referencial metodológico da análise crítica do discurso (ACD) (Chouliaraki \& Fairclough, 1999; Fairclough, 2003, 2009), que entende por discurso os elementos semióticos das práticas sociais: maneiras de as pessoas agirem juntas na prática da produção da vida social. A vida social em si é feita de práticas, que são "modos habituais, ligados a tempos e lugares particulares, em que as pessoas aplicam recursos (materiais ou simbólicos) para agirem juntas no mundo" (Chouliaraki \& Fairclough, 1999, p. 21). Portanto, para a concretização do nosso objetivo, precisamos, inicialmente, compreender o que é a prática da preceptoria em saúde, caracterizá-la, apontar quais os problemas que a envolvem e estudar mais profundamente um deles: a falta de formação pedagógica. Na medida em que apresentamos essa formação como um passo importante na valorização e na qualificação da preceptoria, analisamos, à luz da $\mathrm{ACD}$, os discursos produzidos coletivamente por preceptores que se formaram pedagogicamente, para tentar compreender o modo de apropriação de um discurso "estranho" por esses profissionais. Por fim, tecemos algumas considerações a respeito do processo de construção textual coletiva e sobre o curso de formação pedagógica para preceptores.

\section{A prática da preceptoria em saúde}

A preceptoria em saúde é uma prática pedagógica que ocorre no ambiente de trabalho e de formação profissional em saúde, no momento do exercício clínico, conduzida por profissionais da assistência, com cargo de professor ou não, com o objetivo de construir e transmitir conhecimentos relativos a cada área de atuação e da saúde como um todo, e de auxiliar na formação ética e moral dos alunos e residentes, estimulando-os a atuar no processo de saúde-doença-cuidado, em seus diferentes níveis de atenção, com responsabilidade social e compromisso com a cidadania (Botti \& Rego, 2008, 2010, 2011; Missaka \& Ribeiro, 2011).

Segundo Botti e Rego (2008), o preceptor tem como funções auxiliar graduandos e recém-graduados na construção de soluções para os problemas com os quais se defrontam na sua prática em saúde, e ensinar executando procedimentos e moderando a discussão de casos clínicos, articulando conhecimentos e valores da escola e do 
trabalho em ambiente profissional, estreitando a distância entre teoria e prática; para tanto, deve ter reconhecida competência clínica e domínio técnico-científico sobre o que ensina. De modo geral, o preceptor possui experiência acumulada ao longo da carreira profissional e exerce a função de educador durante sua prática e no cuidado ao paciente, atuando como orientador e incentivador da aprendizagem dos alunos e dos residentes. Além disso, ao possibilitar que percebam e reconheçam suas potencialidades e dificuldades técnicas e pessoais, o preceptor tem papel fundamental nas escolhas profissionais desses alunos e residentes (Botti \& Rego, 2008).

Essa sucinta descrição sobre a preceptoria, que apresentamos, funciona mais como um conceito, e em sua forma ideal, do que propriamente um retrato fiel da realidade. Quando discutimos a preceptoria, com base no que se passa de fato nos diversos ambientes de trabalho e formação, temos a possibilidade de compreender melhor o que é essa prática e o quanto ela se aproxima ou se distancia da conceituação que fizemos.

Em artigo sobre a preceptoria na rede básica do município do Rio de Janeiro, Trajman, Assunção, Venturi, Tobias, Toschi, \& Brant, (2009) identificaram como principais problemas nessa prática o espaço físico reduzido, a carência de recursos, a falta de tempo dos profissionais e o seu despreparo. E, coerente com isso, o mesmo estudo apontou como principais incentivos à preceptoria a melhoria das condições e da infraestrutura de trabalho, a melhor remuneração e a capacitação dos profissionais. A maioria dos profissionais de saúde entrevistados relatou que as atividades de preceptoria faziam parte de suas atribuições e, em consonância com esse achado, disseram que a melhor remuneração pelas atividades como um todo era mais importante do que o complemento salarial pelo exercício da preceptoria.

Em revisão internacional sobre a preceptoria na enfermagem, Omansky (2010) encontrou também resultados semelhantes quanto aos aspectos negativos dessa atividade, apontando como principais problemas: a ambiguidade do papel de preceptor, pois há uma grande distância entre o que se propõe teoricamente para a atividade e o que acontece na realidade, principalmente por não haver um papel muito bem definido, para o preceptor, dos objetivos a serem alcançados com os alunos, ou até mesmo por desconhecê-los totalmente, levando, entre outras coisas, a um estresse laboral; a falta de reconhecimento pelos pares ou pela instituição pelo trabalho extra desenvolvido na preceptoria; e a sobrecarga de trabalho e a falta de tempo, diretamente relacionadas com os outros problemas, causando ainda mais estresse. 
Entre os problemas relatados, o de maior interesse para este trabalho é o da capacitação profissional, mais especificamente o aspecto pedagógico dessa prática, elemento de altíssima relevância quando se pensam os objetivos da preceptoria e sua qualidade, tal como afirmam diversos estudos (Botti \& Rego, 2008, 2010, 2011; Missaka \& Ribeiro, 2011; Nilsson, Pennbrant, Pilhammar, \& Wenestam, 2010; Paton, 2010; Smedley, 2008; Trajman, Assunção, Venturi, Tobias, Toschi, \& Brant, 2009). Como já apontamos, a preceptoria é uma prática de formação profissional, portanto, se desenvolve por processos educativos, os quais se dão das mais diversas formas, nos mais diferentes contextos e nos mais variados cenários de aprendizagem que a rede de atenção à saúde pode oferecer. Há necessidade de que os profissionais de saúde que atuam como preceptores tenham competência didático-pedagógica para desenvolver essa função. Entretanto, o que se vê na prática é justamente o contrário: eles dominam os saberes profissionais - essencial para qualquer tipo de formação -, mas não os saberes pedagógicos, aqueles necessários para a organização de ações formativas, tais como os diferentes processos de ensino-aprendizagem e as diferentes modalidades de avaliação.

Grande parte dos preceptores atua de maneira intuitiva, reproduzindo os modelos de formação pelos quais passaram quando alunos, confundindo transmissão de informação com ensino (Missaka \& Ribeiro, 2011). Como bem apontam Botti e Rego (2011), isso não só ocorre na preceptoria na residência médica, como também se estende às outras categorias profissionais e a outros momentos.

0 preceptor assume vários papéis no processo de formação da residência médica. Algumas vezes mostra o caminho, serve como guia. Outras, estimula o raciocínio e a postura ativa do residente. Muitas vezes planeja, controla o processo de aprendizagem e analisa o desempenho. Mas também aconselha, usando de sua experiência, cuidando do crescimento profissional e pessoal do jovem médico (p.79).

Nesse contexto, Missaka e Ribeiro (2011) discutem a necessidade de os preceptores vivenciarem processos formativos, não fragmentados, e que contribuam para uma reflexão consistente sobre o modelo de atenção à saúde. Para tanto, além do apoio institucional, é preciso pensar em uma estratégia educacional que favoreça uma perspectiva emancipadora e que possibilite refletir criticamente sobre os processos de trabalho, condição fundamental para ampliar “as dimensões realizadoras do trabalho 
em saúde" (p. 308). Os autores defendem o desenvolvimento de cursos de formação pedagógica com o objetivo de proporcionar a apropriação do campo da educação em saúde, de modo a ampliar o olhar dos preceptores para questões sobre educação, trabalho e saúde. Nessa mesma perspectiva, Trajman, Assunção, Venturi, Tobias, Toschi, e Brant, (2009) consideram que a formação pedagógica deve ter como meta

compreender o que significa um processo dialético de ensino-aprendizagem, por meio da adoção de um modelo educativo e de perspectivas pedagógicas que superem a mera transmissão de conhecimentos e que levem os profissionais a extraírem das situações complexas e contraditórias de seus exercícios profissionais diários a possibilidade de superar obstáculos e construir alternativas de solução (p. 31).

Ainda segundo os autores, com o intuito de transformar essas condições adversas e realizar o ideal de saúde universalista da Reforma Sanitária no Brasil, é fundamental que os profissionais elevem sua formação ético-política e profissional.

A necessidade de formação pedagógica não se apresenta descolada da profissionalização da preceptoria como um todo. Em nosso entendimento, isso diz respeito ao nó crítico da preceptoria: a falta de institucionalização dessa prática. Os preceptores atuam nos serviços de saúde, universitários ou não; portanto, o processo de institucionalização deve envolver, principalmente, as secretarias de saúde e as universidades. Na medida em que os serviços de saúde não universitários fazem de seus espaços de assistência também cenários de aprendizagem, eles devem estar estruturados e organizados para que o processo formativo seja desenvolvido de forma adequada. Isso também vale para as universidades, que, embora sejam instituições de ensino, muitas vezes não estruturam e nem organizam seus serviços de saúde como espaços de formação, mantendo-os apenas como de assistência. Destarte, a integração entre secretaria de saúde e universidade é condição a priori para a formação em saúde, bem como para a definição do papel do preceptor em todo este processo, que envolve, entre outras coisas, a construção individual e coletiva de sua identidade, a caracterização de suas funções, a participação ativa na organização curricular e o reconhecimento de sua atividade, material ou simbolicamente (Boyle, Morgan, Layson-Wolf, \& Bittner, 2009).

Diante desse quadro, e na tentativa de colaborar com sua transformação, o Laboratório de Currículo e Ensino do Núcleo de Tecnologia Educacional para a 
Saúde, da Universidade Federal do Rio de Janeiro, deu início, em 2007, a um curso de formação pedagógica de preceptores, que vem sendo, desde então, realizado anualmente. 0 curso está ligado ao projeto “Formação pedagógica dos formadores dos profissionais de saúde: a preceptoria dos Internatos em questão", que tem como objetivo criar, desenvolver e avaliar um modelo de formação pedagógica para preceptores da área da saúde, buscando assim suprir a lacuna existente na formação desse segmento que desempenha importante papel na formação dos profissionais de saúde, seja pelo exemplo prático de suas ações no serviço, seja pela supervisão/orientação dedicada aos alunos em estágio nas unidades de saúde.

O curso é semipresencial e se desenvolve por meio de três módulos temáticos: educação, trabalho e saúde. As primeiras turmas tiveram como público-alvo preceptores médicos do hospital universitário, mas, em 2011, o curso se diversificou e adotou um perfil multiprofissional, além de contar com profissionais de outros serviços de saúde que não apenas desse hospital. Com base em situações-problema, que retratam a rotina do preceptor no serviço público de saúde, promovem-se discussões e reflexões críticas, articuladas com leituras e estudos sobre o tema, e produzem-se sínteses individuais e coletivas. Ao final do curso, os integrantes devem elaborar um trabalho de conclusão que apresente uma proposta de intervenção factível no seu contexto de trabalho. Também são convidados a participar de uma avaliação, usando a livre escrita individual, em que são orientados a escrever sobre a importância e o significado do curso do ponto de vista tanto profissional quanto pessoal.

Como apontamos no início do texto, o objetivo deste trabalho é analisar a construção coletiva de um discurso pedagógico de preceptores do campo da saúde que passaram por um processo de formação pedagógica. Tratou-se, mais especificamente, de analisar as sínteses coletivas do módulo de educação, produzidas pelos preceptores que fizeram o curso no ano de 2011. Tivemos em mente compreender como esses profissionais, oriundos do campo da saúde e em sua maioria com pouco contato com a literatura do campo da educação, se apropriam dos discursos que aí circulam. Pretendemos colaborar para a estruturação e a organização dos diferentes processos de formação de preceptores que têm sido desenvolvidos recentemente no Brasil, bem como, e por que não, de outros tipos de processos de formação pedagógica no campo da saúde, tais como o de professores universitários. 


\section{Análise crítica do discurso}

Optamos pelo referencial metodológico da análise crítica do discurso (ACD) (Chouliaraki \& Fairclough, 1999; Fairclough, 2003, 2009), porque nosso material é fundamentalmente discursivo, além de se alinhar ao objetivo da pesquisa: analisar a construção coletiva de um discurso pedagógico. A ACD se situa no contexto de uma pesquisa crítica sobre as mudanças econômicas, sociais e culturais na sociedade contemporânea. Chouliaraki e Fairclough (1999) apontam que parte significativa das transformações na sociedade contemporânea são transformações no discurso. Além disso, parte daquelas que se desenvolvem fora dos discursos também são moldadas por eles. Todavia, os autores lembram que, apesar da importância social do discurso, não é possível reduzir a vida social a ele, razão pela qual a ACD trabalha com uma visão dialética entre os elementos discursivos e não discursivos do mundo social. Em uma determinada prática social, os diversos elementos da vida são reunidos no que Chouliaraki e Fairclough chamam de “momentos” da prática, em que cada momento é visto como internalizando os outros, sem se reduzir a eles. Os autores descrevem quatro momentos principais: atividade material; relações e processos sociais; fenômenos mentais; e discurso.

Para Fairclough (2009), há três grandes formas em que o discurso se relaciona a outros elementos das práticas sociais e eventos sociais: como uma faceta da ação; na construção (no sentido de representação) de aspectos do mundo; e na constituição de identidades. Nesse sentido, Fairclough $(2003,2009)$ apresenta três categorias analíticas semióticas que correspondem a essas formas: gênero, discurso e estilo. Essas três categorias são explicadas mais adiante, ao longo da análise, para facilitar sua compreensão. Cabe ainda comentar sobre a categoria intertextualidade: a presença em um texto (dimensão semiótica de um evento) de elementos de outros textos, que podem ser relatados de modos diversos, explicitamente demarcados ou não (Chouliaraki \& Fairclough 1999; Fairclough, 2003, 2009).

\section{Discussão}

O material de análise engloba seis sínteses coletivas, cada uma produzida por um grupo diferente, composto de seis a dez preceptores, e cada grupo orientado por uma tutora. 0 curso é desenvolvido segundo o método da aprendizagem baseada em problemas e, nesse contexto, as sínteses são construídas tomando como referência uma questão orientadora de aprendizagem, elaborada coletivamente por meio de discus- 
são de uma situação-problema. Os preceptores do curso foram divididos em duas turmas que ocuparam dois ambientes distintos e, para cada turma, foi elaborada uma questão diferente. As duas turmas foram separadas em seis grupos no total, sendo que cada um deles respondeu à questão que ajudou a construir. Dois grupos responderam à pergunta, "Quais as tendências pedagógicas mais utilizadas no campo da formação em saúde e como aplicá-las no exercício da preceptoria?”, e quatro responderam a "Como desenvolver competências necessárias ao exercício da preceptoria?”.

Para produzir as sínteses, os preceptores escolheram uma estrutura textual que acreditavam ser a mais adequada para responder à questão orientadora de aprendizagem, e que se ajustasse melhor à escrita em grupo. É disso que trata a categoria gênero. Fairclough $(2003,2009)$ descreve os gêneros como modos discursivos de agir e interagir no curso dos eventos sociais. Quando analisamos um texto, em termos de gênero, perguntamos como ele se apresenta e como contribui para ação e interação social nesses eventos. Falar de gênero é falar das formas de ação e interação, é estabelecer a estrutura do aspecto discursivo das práticas como, por exemplo, uma entrevista de trabalho ou um artigo científico. Uma determinada prática social não implica necessariamente em determinado gênero; no curso dos eventos, os agentes podem utilizar diferentes tipos de gêneros, mas, de algum modo, há forte relação entre prática e gênero (Fairclough, 2003). Existe a possibilidade de um texto não ser produzido segundo um único gênero, podendo hibridizar dois ou mais deles (Fairclough, 2003).

Os grupos escreveram suas sínteses segundo dois padrões: o de trabalho monográfico ou redação e o de manual ou tópicos. Em ambos os casos, houve passagens do que poderia ser caracterizado como relato de experiência, em que são tratados tanto o processo de aprendizagem por parte dos preceptores no curso como as experiências próprias na preceptoria, o que podemos observar no trecho:

Mostra disso foi o sentimento de movimento, de aprendizado que vamos ganhando a cada aula. Percebemos o que tínhamos como certo e o que devemos abrir mão como algo potencialmente não produtivo.

No geral, quando o texto é permeado de relatos de experiência, apresenta-se mais leve e real, menos acadêmico, mais próximo de uma apropriação concreta do conteúdo estudado. Isso, provavelmente, porque é feita uma relação de contestação ou confirmação com a prática, com conhecimentos prévios, o que permite uma apropria- 
ção mais significativa. 0 texto com uma estrutura de redação/trabalho monográfico e permeado de relatos de experiência parece ser aquele em que a apropriação se apresenta mais promissora. Devemos pontuar, no entanto, que essa estrutura não necessariamente garante uma boa apropriação de conteúdo. Os autores sentem-se mais seguros para escrever um texto corrido, coerente, coeso, evitando assim um texto fragmentado, por tópicos ou regras, sem identidade.

Um outro fato frequente nos textos estudados é a evolução histórica do processo pedagógico, passando de uma fase tutelada pelo poder para o método da problematização.

Ter domínio da teoria e prática clínica e, dessa forma ... descer do pedestal de detentor do conhecimento e se aproximar da realidade e do nível de conhecimento dos alunos para poder criar, nos mesmos, meios de buscar por conta própria seus mecanismos de construção do saber.

Todavia, a apropriação do conteúdo estudado não necessariamente está relacionada à resposta satisfatória à questão orientadora de aprendizagem. Há um caso de estrutura em tópicos em que a questão orientadora é bem respondida, mas os tópicos são permeados de referências sem uma leitura crítica, apesar de certa coesão interna. No último tópico, a questão orientadora é respondida, o que não evita o texto de se apresentar de forma fragmentada e com uma apropriação insuficiente do conteúdo estudado. Há que se ponderar que os textos são sínteses coletivas, portanto há uma dificuldade inerente ao trabalho de sintetizar as diversas leituras individuais em um único documento, como está exemplificado no fragmento extraído do último tópico da síntese citada:

0 desenvolvimento das competências necessárias ao exercício da preceptoria é um processo contínuo que tem início na graduação. A formação de um profissional completo é o primeiro passo para a formação de bons preceptores. Esse passo depende da implementação das diretrizes curriculares nacionais e de mudanças institucionais. A formação ética também é um processo contínuo e não se encerra na graduação.

Esse caso citado pode ser um exemplo típico, em que cada tópico pode ser retirado de uma síntese individual diferente e, no fim, tem-se apenas uma colagem de 
recortes de sínteses, ou, por outro lado, pode-se ter cada tópico como um resumo do que cada síntese individual trata sobre o tema discutido. Dessa discussão, podemos tirar dois pontos. O primeiro é que a síntese coletiva, em tese, permite que sejam contrastados textos diferentes, produções discursivas diversas, e então debatidos em grupo, e elaborado um possível consenso final - se bem conduzida, é uma rica oportunidade de aprendizado. 0 segundo ponto, que tem relação com o primeiro, é a dificuldade inerente a esse tipo de atividade de produção textual coletiva, sendo árdua a elaboração de um documento coeso que reúna produções individuais, ainda mais no caso do curso, em que os preceptores estão lidando com uma literatura com a qual têm pouca intimidade.

Para esclarecer melhor essa discussão sobre apropriação, estrutura e questões orientadoras de aprendizagem, vamos ao nosso material de estudo. Das seis sínteses coletivas, três responderam à questão orientadora, duas não e uma apenas em parte. Duas dessas sínteses são em formato de tópicos/manual, o que quer dizer que não são textos corridos; em ambos os casos, não há uma coesão do texto como um todo. No entanto, uma dessas sínteses responde apenas em parte à questão orientadora de aprendizagem, definindo competências e elencando uma série delas a serem desenvolvidas pelos preceptores. Outra se aproxima um pouco mais da resposta esperada, como se pode verificar:

Para desenvolver competência, seria necessário, desenvolver o conhecimento técnico na área; a capacidade de se relacionar com alunos, equipe, pacientes e familiares. A competência envolve além do conhecimento, as habilidades, os valores e/ou atitudes.

Nos dois casos, há apropriação parcial do conteúdo geral discutido nos textos estudados. Portanto, não há uma relação direta e obrigatória entre um formato de síntese coletiva e a apropriação de conteúdos e resposta à questão orientadora.

Muito dessas diferenças entre as sínteses se deve ao fato de que cada grupo é orientado por uma tutora diferente, que, apesar de seguir um mesmo padrão dentro do curso, tem um modo próprio de conduzi-lo. Além disso, cada grupo é formado por profissionais de diferentes áreas e especialidades, que podem ter uma relação profissional mais próxima ou não, o que pode facilitar ou dificultar o processo de construção discursiva coletiva; isso sem falar na personalidade e na posição de cada um em relação aos temas discutidos, o que também pode ser um fator favorável ou 
desfavorável para que seja produzida uma síntese coerente e satisfatória de acordo com os objetivos do curso.

Em parte, já discutimos outra categoria analítica da $A C D$, que é o estilo. Fairclough (2003) explica que os estilos são aspectos discursivos dos modos de ser, e estão ligados à identificação: quem você é, é, em parte, uma questão de como você fala ou escreve. Trabalhamos aqui o estilo com foco nos seus dois aspectos principais de análise que são a modalidade e a avaliação. Fairclough (2003) descreve que a modalidade é uma questão de como as pessoas se comprometem com o que dizem; ela é vista em termos das relações dos falantes ou escritores, do "autor", com os discursos. Neves (2011) apresenta quatro tipos de modalidade que variam de acordo com o elemento (verbo, substantivo, advérbio ou adjetivo): a epistêmica, que indica uma crença, uma opinião, uma expectativa sobre uma asserção, e está ligada ao conhecimento; a delimitadora, que delimita o ponto de vista sob o qual uma asserção pode ser considerada verdadeira; a deôntica, que exprime consideração de necessidade por obrigatoriedade, ligada ao dever; e a afetiva, que indica um estado de espírito em relação ao conteúdo da asserção. E a análise pelo aspecto da avaliação se dá pela compreensão dos modos, explícitos ou implícitos, em que o autor se compromete com valores em termos do que é desejável ou indesejável.

A questão do estilo está muito clara no modo como os preceptores se relacionam com as referências usadas nas sínteses (intertextualidade). Em vários momentos eles fazem um uso não crítico das referências. Queremos dizer com isso que há, normalmente, uma relação de aceitação e de compromisso explícito com as referências citadas. Elas são tomadas como verdade, portanto, com modalidade epistêmica trabalhada em alto grau de crença/concordância, valendo-se de expressões como "segundo o autor x", "de acordo com o autor y”, "tal conceito é... (referência)”, sem haver comentários próprios sobre o que dizem os autores. Tem-se claro o uso da intertextualidade como um recurso de construção do documento, funcionando, nesse caso, como uma estratégia de “legitimação por autorização” (Van Leeuwen, s/d, citado em Fairclough, 2003), uma vez que os preceptores se referem a um autor, e se apoiam nele sem ir além da citação, como observado a seguir:

O conceito de competência é complexo e teve ao longo dos vários (e foram muitos) textos lidos, definições diferentes mas que convergiam para uma mesma idéia: $\mathrm{A}$ competência permite mobilizar conhecimentos a fim de se enfrentar uma determina- 
da situação (Garcia, 2005) e pode ser considerada como uma combinação de atributos complexos (conhecimentos, atitudes, valores e habilidades), conceito de autores australianos, conforme o texto com definição de competências de vários países.

Isso pode indicar um problema de apropriação do conteúdo discutido, principalmente por se tratar de uma temática de que os preceptores têm pouca leitura; por terem dificuldade em elaborar um texto argumentativo, próprio das ciências humanas, com as quais não estão acostumados; ou mesmo, como já tratado anteriormente, por sentirem dificuldade em produzir um texto coletivamente, em fazer uma costura coerente de ideias diversas, o que, em tese, é facilitado ao reunir, agrupar algumas referências que tratam do mesmo tema.

Com a modalidade deôntica e a avaliação acontece o mesmo que com a modalidade epistêmica. Há um uso frequente das referências (explícita ou implicitamente, quer dizer, demarcadas ou não) para dizer que é necessária uma ação, tomar uma atitude, assumir um valor etc. Isso tem muito a ver com o fato de o curso ser mais que um processo de formação, pretender ser um processo de transformação de práticas; e por ser um curso de inscrição voluntária, os alunos-preceptores estão frequentemente dispostos a mudar, adotando, assim, as ideias propostas por diferentes autores que abordam o tema da clínica e do ensino em saúde por uma perspectiva que concordam ou que gostariam de assumir. Um exemplo disso pode ser extraído de uma das seis sínteses:

Assim, todo desconforto mobiliza o aprendizado, e que no papel de facilitadores precisamos desenvolver ferramentas para "saber provocar". Como educadores, necessitamos refletir antes de adotar uma determinada prática pedagógica.

Essa discussão que tecemos sobre o estilo não vale para todas as sínteses, mas é uma constante. Há exemplos em que as referências são trabalhadas de forma mais crítica, elaborada, em que os preceptores não assumem determinada citação como verdade ou dever evidente, mas constroem um argumento sobre, expõem alguma discordância ou necessidade de complemento. Isso fica mais evidente em dois textos em que há uma estrutura de redação/trabalho monográfico, permeados por relatos de experiências, como um trecho de uma destas sínteses, imediatamente contestado pelo grupo, como se pode verificar em: 
Paulo Freire foi citado com destaque no campo da educação, mas com posições radicais e inadequadas ao contexto atual, mediante o uso de um discurso de anti-excelência, o que criou polêmica na discussão do grupo.

Em momento posterior, o grupo reconhece, em Paulo Freire, que a autonomia explícita na inovação forneceu os alicerces para as metodologias ativas, que afirma serem fundamentais para a formação de profissionais que possam atuar como sujeitos sociais, com capacidade para intervir em contextos de incertezas e complexidades.

Por fim, vamos tratar de outra categoria analítica da ACD, o discurso. Segundo Fairclough $(2003,2009)$, os discursos são modos de representar aspectos particulares do mundo que podem ser representados de maneira diversa, e os diferentes discursos são diferentes perspectivas sobre o mundo, sendo as suas relações um elemento das relações das pessoas. Um texto específico pode conter um ou mais discursos, e as relações que eles estabelecem podem ser dialógicas ou polêmicas, isto é, podem ser discursos que convergem ou não sobre um ponto de vista (Fairclough, 2003). No nosso caso, os discursos presentes nas sínteses têm, ou deveriam ter, a ver com as questões orientadoras de aprendizagem. E, no geral, têm de fato, apesar de algumas não responderem satisfatoriamente.

Na primeira questão orientadora, “Quais as tendências pedagógicas mais utilizadas no campo da formação em saúde e como aplicá-las no exercício da preceptoria?”, o tema discutido são as tendências pedagógicas. Esse tema pode ser tratado por diversas perspectivas, dependendo da visão que os autores (os preceptores) assumem em relação a ele. Nas sínteses, os preceptores abordam as tendências por uma perspectiva histórica, ao enunciar as principais correntes ao longo dos tempos e na relação com o contexto da época.

A Pedagogia Tradicional foi predominante na educação brasileira até 1930 ... A Pedagogia Renovada predominou no período histórico de 1930 a 1945 com desdobramentos específicos na década de 60... Até hoje esta corrente influencia algumas práticas de ensino .... A Pedagogia por Condicionamento surge no final da década de 60 e durante os anos 70, com o desenvolvimento do processo de industrialização e a ênfase no desenvolvimento econômico. ... A Pedagogia Crítica surge no final da década de 70 e início dos anos 80 , como uma proposta dialética de perceber a relação entre a educação escolar e a sociedade. 
O que mais substancialmente difere os discursos sobre tendências pedagógicas nas sínteses é o modo como os preceptores assumem uma determinada tendência como base para sua prática. Quando tomam a perspectiva histórica, discutem, no geral, tendências tradicionais, tecnicistas e críticas, e como elas fundamentam, ou fundamentaram, as práticas pedagógicas em cada época, inclusive atualmente. A diferença entre as sínteses reside no fato de um grupo assumir por completo uma perspectiva crítica, problematizadora, com metodologias ativas, com foco no estudante. Já o outro grupo não assume essa perspectiva por completo, mas a toma como base, e afirma ser necessário refletir sobre o objetivo de cada atividade, dos conteúdos subjacentes, do contexto e condições de ensino, e aí, sim, adotar uma prática condizente com a situação como um todo. A adoção mais direta de uma pedagogia problematizadora, por parte dos preceptores, nos parece fruto da necessidade de transformação que sentem em sua prática, mesmo porque eles procuram o curso voluntariamente e com o objetivo claro de mudar algo na preceptoria; e o discurso problematizador, em um primeiro momento, se encaixa perfeitamente nisso, ainda mais para quem está descontente com a prática cotidiana, sabidamente tradicional.

Em relação à segunda pergunta, "Como desenvolver competências necessárias ao exercício da preceptoria?”, é difícil estabelecer um relato mais coerente, uma vez que as quatro sínteses que a respondem, ou tentam responder, o fazem de maneira diversa, não há uma linha comum de argumentação. Em parte, essa dificuldade é reflexo da própria discussão sobre competências na literatura, em que não há um consenso em torno de sua conceituação. No geral, quando os preceptores buscaram responder à segunda pergunta, os discursos mais recorrentes foram: os quatro pilares da educação da Unesco (1990) - aprender a conhecer, aprender a fazer, aprender a viver, aprender a ser -; a complexidade e a multidimensionalidade do conceito de competências; a competência como mobilização de conhecimentos, habilidades e valores, tratando-se, normalmente, dos aspectos cognitivos, técnicos e afetivos da prática profissional e educativa, com destaque para os aspectos afetivos. Também encontramos discursos que concordam com a necessidade de transformação na formação em saúde, tomando como referência a própria transformação do sistema de saúde idealizado e concretizado no SUS; há aqueles que tratam a mudança na formação com base nas Diretrizes Curriculares Nacionais para os cursos da saúde, e daí se discute a necessidade de mudança no modelo de ensino, o que geralmente leva à discussão do papel 
do preceptor nesse processo. A discussão do papel do preceptor, naturalmente, é onipresente, independentemente da pergunta, já que se trata de um curso de formação pedagógica de preceptores.

Outro ponto a se destacar é que as sínteses não se atêm à pergunta que as orienta. Quem responde sobre competências também disserta sobre tendências pedagógicas, e vice-versa; isso porque, apesar da produção e da orientação das sínteses coletivas serem em grupos, os preceptores compartilham espaços em que todos se reúnem, os fóruns virtuais são abertos, eles conversam entre si no curso e fora dele sobre seus estudos, e as diversas referências bibliográficas trabalhadas abordam temas diversos e comuns. No que tange ao desenvolvimento das sínteses, o que efetivamente muda de uma para outra é o grau de reflexão sobre a prática da preceptoria em sua relação com os conteúdos estudados no curso e também o quanto os preceptores refletem sobre a própria prática, não sobre uma preceptoria abstrata, idealizada. Podemos afirmar, portanto, que a síntese coletiva é mais interessante e consistente quando: o texto estabelece uma relação crítica com os conteúdos estudados; a experiência concreta de ser preceptor é tomada como base para as reflexões; e a questão orientadora de aprendizagem não é apenas uma disparadora da reflexão, mas o fundamento desta (o que não significa que se deva falar apenas sobre o que pede a questão orientadora). Não há uma síntese coletiva que poderíamos chamar de “modelo" em nosso material analisado, o que, na verdade, não é o mais importante, pois o que nos interessa, realmente, é essa caracterização dos elementos que configuram uma apropriação relevante e consistente do discurso pedagógico por profissionais que não têm aproximação com esse tipo de discurso.

Cabe lembrar que as sínteses coletivas são produtos de uma discussão entre vários sujeitos que desenvolveram uma síntese individual tomando como referência a mesma questão orientadora de aprendizagem, sujeitos que, além de terem discutido entre si, presencial e virtualmente, também responderam às tutoras que orientaram e corrigiram seus trabalhos. Nesse sentido, os preceptores elaboraram a síntese, pensando principalmente em dois "grupos": neles mesmos, e por duas vezes, uma no processo de negociação interna ao grupo e outra por responderem a uma questão de sua própria "autoria"; e nas tutoras (orientadoras e avaliadoras). Por isso, este trabalho não é uma atividade simples. A produção coletiva da síntese é um processo complexo, principalmente se pensarmos no tempo escasso que esses profissionais têm para discutir em grupo, mesmo que tenham disponível um ambiente virtual. 


\section{Conclusão}

Mais do que produzir uma análise sobre o processo de apropriação coletiva de um discurso pedagógico por profissionais que não tinham contato prévio com esse tipo de discurso, nossa perspectiva metodológica também se mostrou um importante instrumento de avaliação do próprio curso de formação pedagógica. Não se tratou apenas de compreender como um discurso “estranho" é apropriado coletivamente em um processo ativo de ensino-aprendizagem, mas também de avaliar a organização do curso e a condução de parte de suas atividades. Este não era um objetivo explícito, quando resolvemos desenvolver este trabalho, mas, ao longo de seu desenvolvimento, ficou claro que a análise crítica do discurso apresenta elementos relevantes que podem ser usados em um processo mais amplo de avaliação do curso como um todo pelos seus organizadores e condutores.

0 estudo coletivo é interessante, na medida em que proporciona o trabalho em grupo, portanto, o exercício do diálogo, da tolerância, da escuta, da troca de saberes, da exposição de leituras diferentes e divergentes sobre determinado assunto. Enfim, é um processo que só tende a enriquecer os envolvidos, se bem organizado e conduzido. 0 desafio reside aí mesmo, principalmente quando se exige uma produção coletiva sobre o estudo, não apenas o debate em si, e foi isso que o nosso trabalho identificou. A escrita coletiva é um processo que demanda tempo, paciência e dedicação, tanto por parte dos professores como dos alunos. Sendo assim, uma atividade desse gênero deve ser muito bem planejada, não há grande margem para improvisações, o que não significa que deva ser algo estanque, fechado, mas, ao tomarmos nosso caso como referência, as variáveis que envolvem uma boa condução do processo são enormes, portanto, é mais difícil de controlá-lo, ainda mais se atentarmos para o fato de que o curso se dirige a profissionais com uma carga horária de trabalho elevada, o que envolve muito estresse e pouco tempo disponível para se dedicar às atividades do curso. Tudo isso vai ao encontro da discussão inicial que tecemos sobre a preceptoria, uma vez que ainda é uma atividade pouco institucionalizada e, por conseguinte, sem maior valorização e organização. 0 curso de formação pedagógica não é a chave para todos os problemas que envolvem a preceptoria, mas, com certeza, pode colaborar e muito para a estruturação dessa prática. 


\section{Referências bibliográficas}

Botti, S. H. de O., \& Rego, S. (2008). Preceptor, supervisor, tutor e mentor: quais são seus papéis?. Revista Brasileira de Educação Médica, 32(3), 363-73.

Botti, S. H. de O., \& Rego, S. T. A. (2010). Processo de ensino-aprendizagem na residência médica. Revista Brasileira de Educação Médica, 34(1), 132-140.

Botti, S. H. de O., \& Rego, S. T. de A. (2011). Docente clínico: o complexo papel do preceptor na residência médica. Physis Revista de Saúde Coletiva, 21(1), 65-85.

Boyle, C. J., Morgan,J. A., Layson-Wolf, C., \& Bittner, M. R. de. (2009). Developing and implementing an academy of preceptors. American Journal of Pharmaceutical Education, 73(2), 1-10.

Chouliaraki, L., \& Fairclough, N. (1999). Discourse in late modernity: rethinking critical discourse analysis. Edinburgo: Edinburgh University Press.

Fairclough, N. (2003). Analysing discourse: textual analysis for social research. Londres: Routledge.

Fairclough, N. (2009). A dialectical-relational approach to critical discourse analysis in social research. In R. Wodak \& M. Meyer. Methods of critical discourse analysis (2a ed.). Londres: Sage Publications.

Missaka, H., \& Ribeiro, V. M. B. (2011). A preceptoria na formação médica: o que dizem os trabalhos nos Congressos Brasileiros de Educação Médica 2007-2009. Revista Brasileira de Educação Médica, 35(3), 303-10.

Neves, M. H. de M. (2011). Gramática de usos de português. 2a ed. São Paulo: Editora Unesp.

Nilsson, M. S., Pennbrant, S., Pilhammar, E. , \&, Wenestam, C.G. (2010). Pedagogical strategies used in clinical medical education. BMC Medical Education, 10(9), 1-10.

Omansky, G. L. (2010). Staff nurses' experiences as preceptors and mentors: an integrative review. Journal of Nursing Management, 18, 697-703.

Paton, B. I. (2010). The professional practice knowledge of nurse preceptors. Journal of Nursing Education, 49(3), 143-9.

Smedley, A.M. (2008). Becoming and being a preceptor: a phenomenological study. The Journal of Continuing Education in Nursing, 39(4),185-91.

Trajman, A., Assunção, N., Venturi, M., Tobias,D., Toschi, W. \& Brant, V. (2009). A preceptoria na rede básica da secretaria municipal de saúde do Rio de Janeiro: opinião dos profissionais de saúde. Revista Brasileira de Educação Médica, 33(1), 24-32.

Submetido à avaliação em 10 de outubro de 2013; aceito para publicação em 19 de setembro de 2014. 